\title{
QUIÉN TE HA VISTO Y QUIÉN TE VE. DE LOCUCIONES, FORMACIONES PAREMIOLÓGICAS Y JUICIOS DE VALOR EN LA \\ CRÓNICA TROIANA GALLEGA*
}

\author{
QUIÉN TE HA VISTO Y QUIÉN TE VE. CONCERNING IDIOMS, \\ PROVERBS AND VALUE JUDGMENTS IN THE GALICIAN CRÓNICA \\ TROIANA
}

Francisco Pedro Pla Colomer

Universidad de Jaén

fpla@ujaen.es

\begin{abstract}
RESUMEN
La presente investigación tiene como finalidad el estudio de los tipos fraseológicos, en especial, los circunscritos al ámbito de la paremiología que se documentan en el testimonio gallego de la materia troyana emanada del Roman de Troie de Benoit de Saint-Maure: la Crónica troiana (c. 1373). De esta manera, se da continuidad a otro trabajo en el que se contrastan las unidades fraseológicas de esta obra con otros textos de materia troyana de ámbito peninsular. Todo ello permitirá describir con mayor profundidad el estadio variacional de las expresiones fijas del occidente peninsular reflejadas en una de las líneas traductológicas más fecundas del medioevo.
\end{abstract}

Palabras clave: literatura hispánica medieval; materia de Troya; traducciones medievales; fraseología histórica.

\begin{abstract}
The current research has the aim to analyse the typological idioms (specially the proverbs) documented in the Galician testimony emanated from the Roman de Troie of Benoit de Saint-Maure: the Crónica troiana (c. 1373). These results will become the second part of a research concerning the description of the idioms of this text in contrast with other peninsular testimonies related with the matter of Troy. All of that will allow us to describe more accurately the variational state of the idioms in the Peninsular West corresponding to one of the more productive branches of the medieval translations.
\end{abstract}

Keywords: Medieval Spanish Literature; Troy subject; Medieval translation; Historical Phraseology.

\footnotetext{
* Este trabajo se inscribe en el proyecto Historia e historiografía de la lengua castellana en su diacronía contrastiva (HISLECDIAC) con referencia FFI2017-83688-P, financiado por la Agencia Estatal de Investigación (AEI) y el Fondo Europeo de Desarrollo Regional (FEDER) y gestionado por la Universidad de Valencia a través del Departamento de Filología Española. El proyecto forma parte del Programa Estatal de Fomento de la Investigación Científica y Técnica de Excelencia, Subprograma Estatal de Generación de Conocimiento y está dirigido por la Dr. ${ }^{a}$ M. ${ }^{a}$ Teresa Echenique Elizondo y la Dr. ${ }^{a}$ M. ${ }^{a}$ José Martínez Alcalde
} 


\section{TEXTOS PENINSULARES DE MATERIA TROYANA: A MODO DE INT'RODUCCIÓN}

Esta investigación forma parte de un estudio en conjunto con el Dr. Vicente Llavata (Universitat de València) en torno a la recepción de la materia troyana y su plasmación textual en los diferentes espacios peninsulares a lo largo de los siglos XIII y XV (Pla y Vicente, 2017 y 2018). De este corpus de trabajo, y a partir de una metodología filológica integral, es posible extraer datos contextuales significativos a la hora de abordar, tanto el estudio histórico-contrastivo de los usos fraseológicos representados en el ámbito hispánico, como los rasgos expresivos que configuran el discurso lingüístico de estos textos en sus distintos ámbitos semánticos (tales como la esfera del amor o la guerra). A su vez, los datos arrojados permitirán establecer líneas de recepción traductológica no solo en su nivel vertical, en contraste con sus fuentes primarias, sino también en una perspectiva horizontal, más integradora, para constatar la influencia mutua entre los testimonios peninsulares emanados de las dos vertientes principales de la materia troyana en Europa: la procedente del Roman de Troie (11551165) de Benoît de Sainte-Maure, y la Historia destructionis Troiae de Guido delle Colonne ${ }^{1}$.

En este caso en concreto, tras haber abordado en otra investigación la descripción tipológica de los usos locucionales de la Crónica troiana gallega ( $\mathrm{Pla}$, en prensa a), muchos de ellos en su estadio variacional y todavía en proceso de formación (Lapesa, 1992; Echenique, 2003 y 2008; Echenique y Martínez, 201355; Echenique, Martínez y Sánchez, 2016), se centra el punto de atención en las formas paremiológicas y las expresiones propias de los juicios de valor empleados en el ámbito de recepción de la zona occidental peninsular. Cada una de las formas idiomáticas documentadas en la obra responde a diversas circunstancias sujetas a patrones de adaptación propios del diasistema lingüístico o motivadas por los imperativos del proceso de traducción, así como de las características configurativas de la tradición textual de la que deriva, en este caso, la del Roman de Troie.

\footnotetext{
${ }^{1}$ Los textos peninsulares correspondientes a la línea derivada de la Historia destructionis Troiae forman parte del campo de estudio del Dr. Vicente Llavata (2011 y 2016).
} 
En un primer estadio de este proyecto de investigación tuvo lugar el análisis contrastivo de los primeros testimonios peninsulares sobre la materia de Troya, es decir, las estrofas 335 a 773 del Libro de Alexandre, en contraste con la Historia troyana polimétrica (en prosa y verso), la obra latina de Guido delle Colonne y la versión aragonesa de la Crónica troyana promovida por Juan Fernández de Heredia (Pla y Vicente, 2017). Más adelante, en una segunda etapa de la investigación, se introdujo la Crónica troyana promovida por Alfonso Onceno (c. 1350) y otras versiones catalanas, castellanas y portuguesas derivadas de la Historia destructionis Troiae (Pla y Vicente, 2018), razón por la que se hace necesario ampliar el corpus de trabajo en las direcciones señaladas, en este caso, en la versión gallega de la obra emanada del scriptorium de Alfonso Onceno.

\section{CRÓNICA TROIANA: MODELO TRADUCTOLÓGICO DEL TRESCIENTOS}

En el proceso traductológico de la obra de Benoît de Sainte-Maure, las traducciones peninsulares imprimieron cierto carácter genuino que oscilaba entre la fidelidad al texto original y la acomodación del contenido de la obra según las necesidades históricoculturales de cada momento. Si bien es cierto que los textos peninsulares siguen de cerca el Roman de Troie, que se abría con la conquista del vellocino de oro y terminaba con la muerte de Odiseo, es precisamente en el empleo de los rasgos lingüísticos donde se constata el desarrollo original de las esferas estilístico-expresivas concernientes, entre otros, a los discursos militares o las escenas amorosas.

La traducción gallega ${ }^{2}$, fechada hacia el siglo XIV, se ha transmitido en un único testimonio (ms. 10233, Biblioteca Nacional de Madrid), terminado de copiar en 1373 (Lorenzo, 1993: 192). Esta labor de traducción, en la que convergen la figura de traductor y copista, estuvo promovida por el conde Fernán Pérez de Andrade y fue llevada a cabo por el clérigo Fernán Martís para los primeros 100 folios, en tanto que

\footnotetext{
${ }^{2}$ Ya entrados en la segunda mitad del trescientos, en el espacio lingüístico occidental (Echenique y Sánchez, 2005) existen evidencias en los testimonios conservados que permiten constatar atisbos diferenciales suficientes entre los rasgos lingüísticos gallegos de los portugueses, hecho que permite a Lorenzo (1985, p. 82) afirmar que el gallego es la lengua vehicular empleada en la Crónica troiana tanto por Fernán Martís como por el resto de amanuenses.
} 
para el resto de la obra (los 85 restantes, a falta del primer cuaderno perdido, correspondiente a los versos 1-2078 del Roman de Troie) se observan claros indicios de manos de otros copistas, cuyos rasgos lingüísticos oscilan entre las soluciones propias del gallego y el portugués.

Esta obra deriva directamente (capítulo a capítulo) de la traducción castellana promovida por Alfonso Onceno, compuesta durante su reinado y terminada de historiar en el de Pedro I (Pla, 2019) ${ }^{3}$. En muchas ocasiones, la libertad del traductor ocasiona desvíos derivados de una mala lectura, omisiones, interpolaciones, alteraciones o, incluso, errores de interpretación. No obstante, no es posible aplicar sistemáticamente esta perspectiva en cuanto al contenido fraseológico de las mismas, en tanto, del mismo modo que en la traducción castellana el contenido fraseológico se acomoda a la tradición locucional de un diasistema dado, lo mismo ocurre con la traducción gallega y, por tanto, no deben tratarse de errores de transmisión o fallos del traductor. Además, ambos textos comparten el mismo tipo de usos locucionales para los ámbitos del amor cortés y la militia, así como carecen de expresiones fijas en las partes más descriptivas.

\section{TIPOLOGÍA Y USOS LOCUCIONALES EN LA CRÓNICA TROIANA}

La rica variación fraseológica que ofrece la versión gallega forma parte de los modos traductológicos de adaptación de las locuciones y otras expresiones (cuasi)fijas del texto castellano promovido por Alfonso Onceno. El proceso de traducción en la Baja Edad Media no consistía exclusivamente en la adecuación sistemática de un sistema lingüístico a otro, todo lo contrario, si bien es cierto que se documentan locuciones que comparten el mismo significante lingüístico, sobresale en la obra gallega una riqueza de variantes en convivencia que no siempre encuentran correspondencia con la obra castellana (o viceversa, en tanto el traductor gallego omite estructuras fraseológicas del texto castellano), bien por las propias diferencias halladas entre diasistemas lingüísticos diferentes, bien por la finalidad que persigue cada uno de los

\footnotetext{
${ }^{3}$ No resulta imposible pensar que la traducción promovida por el monarca castellano no tuviera como punto de partida directo el original francés, sino que lo más probable es que mandara volcar al castellano una traducción anterior del Roman de Troie con claros rasgos occidentales, versión que desconocería Pérez de Andrade cuando mandó traducir esta nueva versión castellana al gallego.
} 
textos en aras de construir un discurso más breve y directo, frente a otras partes caracterizadas por interpolaciones, glosas u otros mecanismos propios de la amplificatio.

El contraste detallado de cada expresión fraseológica documentada en los dos textos citados ha conducido a establecer una tipología de los usos locucionales, al margen de posibles variantes como consecuencia de errores interpretativos o de lectura. Con ello, se pretende aportar un panorama general del tratamiento de las expresiones fijas en las traducciones del trescientos con la finalidad de adecuar con mayor concreción el estudio de las paremias:

(i) Correspondencias idénticas entre las expresiones castellanas y gallegas, tanto en el nivel formal, como en lo que concierne a los usos de variantes sinonímicas que comparten un mismo campo semántico:

\begin{tabular}{|c|c|}
\hline CRÓNICA TROYANA CASTELLANA & CRÓNICA TROIANA GALLEGA \\
\hline e que lo farían muy de grado (p. 188) & o fariã moy de grado (p. 216) \\
\hline somos de consuno (p. 193) & somos de cõsún (p. 218) \\
\hline e darles hemos en las cuestas (p. 196) & darlles emos ẽnas costas (p. 219) \\
\hline todo ardía con mal talante (p. 239) & todo ardía cõ mao talẽt (p. 237) \\
\hline $\begin{array}{l}\text { non toviere por bien, e quien non les } \\
\text { diere el galardón (p. 251) }\end{array}$ & $\begin{array}{l}\text { nõ touer por ben et quen lles nõ der o } \\
\text { galardón (p. 242) }\end{array}$ \\
\hline leváronlos de cuestas (p. 289) & leuárõnos de costas (p. 256) \\
\hline $\begin{array}{l}\text { E conséjovos que non ayades en esto } \\
\text { seso de mogo (p. } 367 \text { ) }\end{array}$ & $\begin{array}{l}\text { Et cõsséllouos que nõ aiades en esto siso } \\
\text { de moço (p. 292) }\end{array}$ \\
\hline $\begin{array}{l}\text { que a poco de tiempo le ovieran de } \\
\text { cortar la cabeça (p. 465) }\end{array}$ & $\begin{array}{l}\text { que, a pouco de tenpo, lle ouueran de } \\
\text { cortar a cabeça (p. } 343)\end{array}$ \\
\hline $\begin{array}{l}\text { bien cuidara morir con desseos e con } \\
\text { cuidado d'él (p. 667) }\end{array}$ & $\begin{array}{l}\text { ben coydara a morrer cõ deseios et cõ } \\
\text { coydado del (p. } 420)\end{array}$ \\
\hline $\begin{array}{l}\text { que pudiesse dezir en latín nin en } \\
\text { romançe las fechuras (p. } 679 \text { ) }\end{array}$ & $\begin{array}{l}\text { que podesse dizer en latĩ nẽ en rromãço } \\
\text { as feyturas (p. } 425)\end{array}$ \\
\hline E a ojo veo el mi grand daño (p. 805) & et a ollo ueio o meu grã dãno (p. 490) \\
\hline $\begin{array}{l}\text { él escrivió dos * cartas partidas por } A . \\
\text { B. C. (p. } 1387 \text { ) }\end{array}$ & $\begin{array}{l}\text { el scriuío duas cartas partidas per } \\
\text { A.B.C. (p. } 692 \text { ) }\end{array}$ \\
\hline
\end{tabular}


(ii) Expresiones idiomáticas gallegas formalmente similares a las castellanas, en cuyo proceso de traducción se ven modificadas debido a patrones gramaticales requeridos por la lengua meta:

\begin{tabular}{|c|c|}
\hline CRÓNICA TROYANA CASTELLANA & CRÓNICA TROIANA GALLEGA \\
\hline mas ivan todos * de rendón (p. 386) & Mays ýan todos en rrendón (p. 307) \\
\hline $\begin{array}{l}\text { corriendo por tras de un tendejón (p. } \\
616 \text { ) }\end{array}$ & per tras hũ (p. 401) \\
\hline $\begin{array}{l}\text { fue ferir a Deífebus de todo su poder (p. } \\
860 \text { ) }\end{array}$ & $\begin{array}{l}\text { fuj ferir a Deýfebus, a todo seu poder } \\
\text { (p. 508) }\end{array}$ \\
\hline
\end{tabular}

(iii) Correspondencias léxicas sinonímicas ${ }^{4}$ :

\begin{tabular}{|l|l|}
\hline \multicolumn{1}{|c|}{ CRÓNICA TROYANA CASTELLANA } & \multicolumn{1}{|c|}{ CRÓNICA TROIANA GALLEGA } \\
\hline por aquella ocasión (p. 213) & por aquela enqueigón (p. 228) \\
\hline $\begin{array}{l}\text { E ruégovos que metades toda vuestra } \\
\text { puña en cobrarla (p. 232) }\end{array}$ & $\begin{array}{l}\text { Et rrógouos que façades todo uosso poder } \\
\text { en cobrarla (p. 235) }\end{array}$ \\
\hline $\begin{array}{l}\text { E fabló con ellos con grand seso (p. } \\
\text { 585) }\end{array}$ & Et falou cõelles per grã peça (p. 389) \\
\hline ca oy en este día mató tres (p. 685) & que oie en esta ora matou tres (p. 430) \\
\hline fizo poco recabdo (p. 1090) & fezo pouco siso (p. 586) \\
\hline
\end{tabular}

\footnotetext{
${ }^{4}$ Nótese que para Lorenzo (1985, p. 180), la documentación de estas variantes que no se corresponden literalmente a la estructura de la fuente castellana responden a casos de "sustitución dunha palabra por outra", así como las variantes gramaticales propias de cada diasistema, las engloba en el epígrafe "sustitución dunhas formas por outras" (Lorenzo, 1985, pp. 180-181). A la luz de los datos aquí expuestos, las variantes documentadas que formalmente se distancian de la versión castellana encuentran correspondencia en modos de traducción y procesos de acomodación según las posibilidades lingüísticas permitidas en el paradigma de lengua meta.
} 
(iv) Empleo de formas libres gallegas que encuentran correspondencia con estructuras fijas en castellano y viceversa:

\begin{tabular}{|l|l|}
\hline \multicolumn{1}{|c|}{ CRÓNICA TROYANA CASTELLANA } & \multicolumn{1}{|c|}{ CRÓNICA TROIANA GALLEGA } \\
\hline $\begin{array}{l}\text { lo fendió de çima fasta en fondón (p. } \\
682)\end{array}$ & de çima ata fondo (p. 427) \\
\hline $\begin{array}{l}\text { E assentávasse a par de Troilo (p. } \\
1039)\end{array}$ & Et asentáuase cabo Troilos (p. 567) \\
\hline $\begin{array}{l}\text { ca a fiera guisa avemos menoscabado } \\
\text { (p. 1084) }\end{array}$ & $\begin{array}{l}\text { ca ferament auemos meoscabado (p. } \\
584)\end{array}$ \\
\hline $\begin{array}{l}\text { E dávanles manteniente de parte de las } \\
\text { espaldas (p. 387) }\end{array}$ & $\begin{array}{l}\text { Et dáuãlles a mãtenẽt, de parte das } \\
\text { espaldas (p. 308) }\end{array}$ \\
\hline
\end{tabular}

(v) Variantes fraseológicas gallegas que no se documentan en el texto castellano, así como la supresión de locuciones castellanas en el proceso de traducción:

\begin{tabular}{|l|l|}
\hline \multicolumn{1}{|c|}{ CRÓNICA TROYANA CASTELLANA } & \multicolumn{1}{|c|}{ CRÓNICA TROIANA GALLEGA } \\
\hline $\begin{array}{l}\text { vinieron allí aquella fiesta, a grand } \\
\text { plazer e a grand viçio a fazer sus } \\
\text { sacrificios (p. 278) }\end{array}$ & $\begin{array}{l}\text { Et as gentes todas }[\emptyset] \text { fazíã y moy } \\
\text { grãdes sacrificios (p. 252) }\end{array}$ \\
\hline $\begin{array}{l}\text { ca fieramente lo amava de todo su } \\
\text { coraçón e todo su coraçón en él era ya } \\
\text { tornado e puesto fuera de Troilus (p. } \\
\text { 955) }\end{array}$ & $\begin{array}{l}\text { ca ferament o amaua [Ø], et todo seu } \\
\text { coraçõ en el era ja tornado et posto } \\
\text { fora de Troylos (p. 540) }\end{array}$ \\
\hline $\begin{array}{l}\text { E llamávanlos en su lenguaje, por } \\
\text { grand denuesto, "fistelidas" (p. 1359) }\end{array}$ & $\begin{array}{l}\text { en sua linguaiem }[\varnothing] \text { 'festilidos' (p. } \\
\text { 683) }\end{array}$ \\
\hline $\begin{array}{l}\text { E abraçávanlo e besávanlo, }[\varnothing] \text { ca lo } \\
\text { amavan de coraçón (p. 377) }\end{array}$ & $\begin{array}{l}\text { Et abraçáuãno et beigáuãno, sen mays } \\
\text { tardar, que o amauã de coraçõ (p. } \\
299)\end{array}$ \\
\hline
\end{tabular}

(vi) Simplificación de estructuras idiomatizadas y otros usos locucionales que conllevan diferencia de significado:

\begin{tabular}{|l|l|}
\hline \multicolumn{1}{|c|}{ CRÓNICA TROYANA CASTELLANA } & CRÓNICA TROIANA GALLEGA \\
\hline $\begin{array}{l}\text { cuando ponían sus treguas de un mes } \\
\text { o de más o de menos (p. 310) }\end{array}$ & de hũ mes ou de mays (p. 266) \\
\hline $\begin{array}{l}\text { assí só preso e cuitado de amor (p. 826) } \\
\begin{array}{l}\text { e echeme a dormir a sombra de un } \\
\text { árbol (p. 259) }\end{array}\end{array}$ & $\begin{array}{l}\text { que así sõo coytado d'amor (p. 497) } \\
\text { áruore (p. 245) }\end{array}$ \\
\hline
\end{tabular}




\section{FRASEOMETRÍA, ESTRUCTURAS PAREMIOLÓGICAS Y OTROS JUICIOS DE VALOR}

El enorme caudal variacional que pone de manifiesto el estudio tipológico de las locuciones en su proceso traductológico se ve enriquecido por las paremias, o formas cuasiparemiológicas, documentadas tanto en la obra castellana como en la traducción gallega. En otro trabajo (Pla, 2019) se ha dado cabida al estudio particular de cada uno de los refranes o proverbios castellanos de la obra promovida por el monarca Justiciero para llegar a concluir que el ritmo y la métrica se erigen como constituyentes esenciales, aunque no exclusivos, de la evolución paremiológica, entendida como parte de una teoría fraseométrica 5 .

El alto grado de fijación de estas estructuras, muchas de ellas caracterizadas ya hacia mediados del siglo XIV por claros patrones isorrítmicos e isométricos (/Muy loco es a quien el loco tresquila/ esp. [óo óo óo óo oóo] ${ }^{6}$ o / Cabra va por viña, cual firo la madre, tal firo la fija/esp. [óo óo óo / oóo oóo / oóo oóo] ${ }^{7}$ ) e incluso por la existencia de rimas consonantes (/Faz bien e non cates a quien/, esp.) parecieron ser compartidos también por otros sistemas lingüísticos, conocedores de dichas sentencias "populares", como es el caso del gallego. En el proceso de traducción de estas formas no se recurre a expresiones sinonímicas, sino que se reproducen literalmente con el mantenimiento del mismo tipo de ritmo y de rimas de cada una de ellas, hecho que conduce al traductor a mantener inalteradas las variantes en proceso de fijación, incluso en el caso de que en su propia lengua existieran otras expresiones paremiológicas sinonímicas (/ suele arder el justo por el pecador/ esp. - / sol arder o justo porlo pecador/ gall.; / me entra por la una oreja e me sale por la otra/ esp. - / me entra per hũ a orella et me sal perla outral gall.):

\footnotetext{
${ }^{5}$ A pesar de que muchos refranes no han mantenido una forma isosilábica con rima interna, sí parece haberse establecido una suerte de isorritmia generalizada que ha permitido su pervivencia a lo largo de la historia y que los ha diferenciado de sentencias o adagios, entre otras estructuras.

${ }^{6}$ Endecasílabo mixto en el que predomina el ritmo trocaico llano.

${ }^{7}$ Refrán cuyo ritmo es claramente divisible en tres hexasílabos, uno trocaico llano y dos dactílicos, respectivamente.
} 


\begin{tabular}{|c|c|}
\hline CRÓNICA TROYANA CASTELLANA & CRÓNICA TROIANA GALLEGA \\
\hline $\begin{array}{l}\text { ca diz el proverbio antigo que de los } \\
\text { escarmetados se fazen los arteros (p. 428) }\end{array}$ & $\begin{array}{l}\text { ca dyz o prouerbio antigo que dos } \\
\text { escarmentados sse fazẽ os arteyros (p. } 325)\end{array}$ \\
\hline $\begin{array}{l}\text { e porque diz el proverbio: "Mal de } \\
\text { muchos confuerto es" (p. } 627 \text { ) }\end{array}$ & $\begin{array}{l}\text { et porque diz o prouerbio: "mal de } \\
\text { moytos côforto he" (p. } 405)\end{array}$ \\
\hline $\begin{array}{l}\text { E, por ende, diz el proverbio antigo: } \\
\text { "Faz bien e non cates a quien" (p. 638) }\end{array}$ & $\begin{array}{l}\text { Et por ende diz o prouerbio: } \\
\text { "amigo } 8 \text {, faz ben et nõ cates a quen" ( } \mathrm{p} \text {. } \\
409)\end{array}$ \\
\hline $\begin{array}{l}\text { E comoquier que el proverbio diga } \\
\text { que mal de muchos confuerto es (p. 929) }\end{array}$ & $\begin{array}{l}\text { Et a cõmoquer que o prouerbio diga } \\
\text { que "mal de moytos côforte he" (p. 530) }\end{array}$ \\
\hline $\begin{array}{l}\text { E por tal fecho como este oí dezir } \\
\text { que suele arder el justo por el pecador (p. } \\
950)\end{array}$ & $\begin{array}{l}\text { cõmo este oý dizer que sol arder o justo } \\
\text { porlo pecador (p. 538) }\end{array}$ \\
\hline $\begin{array}{l}\text { E todo esto me entra por la una oreja e } \\
\text { me sale por la otra (p. } 963 \text { ) }\end{array}$ & $\begin{array}{l}\text { Et todo esto me entra per hũa orella et } \\
\text { me sal perla outra (p. } 542)\end{array}$ \\
\hline $\begin{array}{l}\text { Muy loco es a quien el loco tresquila (p. } \\
1327 \text { ) }\end{array}$ & $\begin{array}{l}\text { Moy louco be a quẽ louco trosquia (p. } \\
672 \text { ) }\end{array}$ \\
\hline $\begin{array}{l}\text { E por esto diz el proverbio: "Cabra } \\
\text { va por viña, cual fizo la madre, tal fizo la } \\
\text { fija" (p. 1491) }\end{array}$ & $\begin{array}{l}\text { Et por esto diz o prouerbio: "cabra } \\
\text { uay per vjna, qual fuj a madre tal será a } \\
\text { filla" (p. } 734 \text { ) }\end{array}$ \\
\hline
\end{tabular}

De igual modo ocurre con otras dos estructuras bimembres que, aunque no parece que hayan dejado una huella pertinente en la historia de la paremiología hispánica, presentan claros patrones de regularidad isométrica (en este caso por la alternancia de los ritmos trocaicos y dactílicos en los dos miembros octosílabos), aunque carecen de rima: / Tal cuida su mal a vengar que acreçerá en su deshonra/ esp. (oóo oó ooó / òooó ooóo) ${ }^{9}$ y / quien grand salto quiere saltar, de lueñe deve correr/ esp. (òoóo òooó / oóo óo oó(o)) ${ }^{10}$. Dicha estabilidad se documenta inalterada en la traducción del texto gallego, como se corrobora en la acomodación palabra a palabra de las mismas (/ tal coyda seu mal a ũ̃gar que acrę̧ẽta en sua desonrra/ gall. y / quen grã salto quer saltar, de longe deue correr/ gall.):

\footnotetext{
${ }^{8}$ Posible error de lectura de <antigo $>$ de la fuente castellana, en tanto la introducción de dicho elemento léxico rompe con la isorritmia propia de la paremia: / faz ben et nõ cates a quen/ (oó oó óo oó).

${ }^{9}$ Dos octosílabos de claro ritmo dactílico (con acento cada dos sílabas métricas).

${ }^{10}$ Paremia bimembre compuesta por dos octosílabos, en este caso, el primero de ellos de ritmo mixto (trocaico y dactílico) y el segundo, trocaico con anacrusis.
} 


\begin{tabular}{|c|c|}
\hline CRÓNICA TROYANA CASTELLANA & CRÓNICA TROIANA GALLEGA \\
\hline $\begin{array}{l}\text { ca el proverbio, que nunca suele } \\
\text { mentir de ninguna cosa, dize que } \\
\text { "Tal cuida su mal a vengar que acreçerá en } \\
\text { su deshonra" (p. 213) }\end{array}$ & $\begin{array}{l}\text { Ca o prouerbio, que nũca sol mẽtir } \\
\text { de njhũa cousa, diz que "tal coyda seu } \\
\text { mal a ũ̃gar que acreçẽta en sua desonrra" } \\
\text { (p. 228) }\end{array}$ \\
\hline $\begin{array}{l}\text { E quien grand salto quiere saltar, de lueñe } \\
\text { deve correr (p. 258) }\end{array}$ & $\begin{array}{l}\text { Et quen grã salto quer saltar, de longe deue } \\
\text { correr (p. 244) }\end{array}$ \\
\hline
\end{tabular}

Sobresale en esta obra una estructura en claro proceso de formación que desembocará en la actual /Quién te ha visto y quién te ve/ ${ }^{11}$. Este refrán no encuentra abundante documentación en los textos conservados, en tanto parece recogerse por vez primera en los compendios de refranes y frases hechas por Gonzalo Correas en su Vocabulario de refranes de 1624 (Combet, 1967: 410): / Kien te vido i te ve agora, ¿kuál es el korazón ke no llora? $/{ }^{12}$, cuya primera parte presenta ya indicios de estabilidad rítmica en un octosílabo trocaico llano (óo óo òo óo). Otras fuentes apuntan a Fray Antonio de Guevara, quien en la primera mitad del siglo xvi habría relacionado el origen de esta expresión con la de una revuelta en Ávila relacionada con el derecho regio de gobernar por parte de Juan de Padilla ${ }^{13}$.

${ }^{11}$ Para Cantera (2012, p. 672): "Se dice a veces al darse uno cuenta de la decadencia de una persona o de alguna cosa o de una situación en otro tiempo próspera o de buen ver. También se dice para referirse a un cambio de situación muy importante en una persona ya sea para bien ya sea para mal”.

${ }^{12}$ Nótese que parece ser común en el ámbito peninsular introducir una segunda parte en este refrán, no solo en la variante que ofrece Correas / ¿kuál es el korazón ke no llora?/, sino también en otras formas castellanas / iQuién te ha visto y quien te ve, Bartolomé!/ o del ámbito catalán / QQui t’ha vist o qui et veu, mateta de fenoll/. Recuérdese, asimismo, el título de la obra teatral de Miguel Hernández de 1932 Quién te ba visto y quién te ve y sombra de lo que eras.

${ }_{13}$ Es el caso que recoge el blog dedicado a Dichos populares (http://www.ciudadreal.es/varios/dichos/q.php), en el que se puede leer, recogido bajo la letra Q: "Según cuenta el obispo de Mondoñedo, fray Antonio de Guevara, en tiempos de las revueltas de las Comunidades de Castilla había en un pueblo de Ávila un clérigo de origen vasco, partidario y ferviente defensor del líder de la revuelta Juan de Padilla, a quien señalaba desde el púlpito como "verdadero rey de Castilla, y no el tirano que ahora nos gobierna". Pero resultó que, una vez, el propio rebelde Juan de Padilla apareció con sus tropas y, tal como era la costumbre de la época, devastó las bodegas del lugar para abastecer a sus huestes. Una vez que se fue, el clérigo del lugar subió de nuevo al púlpito y habló al pueblo, pero ahora con un mensaje distinto, diciendo "habéis visto cómo pasó por aquí don Juan de Padilla y cómo sus soldados no me dejaron gallina viva, no tocino, ni estaca, ni tinaja sana. Os digo esto porque, de aquí en adelante, no deberéis rogar a Dios por él, sino por el rey don Carlos y la reina doña Juana, únicos reyes verdaderos...". Como es de suponer, la gente comenzó a aplicar la frase ¡quién te ha visto y quién te ve! para referirse al sentimiento que despierta una persona que en un tiempo fue pujante, feliz, sana o rica y ahora se encuentra débil, triste, enferma o pobre". 
Sin embargo, la relación de este refrán con el sentido de 'decadencia de una situación en otro tiempo próspera' se deja sentir con claridad en la estructura castellana IQuien te en otro tiempo vio, si te agora viesse/ (óo óo óo ó / óo óo óo) ${ }^{14}$, curiosamente con un nivel de fijación similar en lengua gallega, pero con usos léxicos cercanos a la forma conservada, / quen en outro tẽpo wise et quen [te] agora uee/ (óo óo óo óo / óo óo óo) ${ }^{15}$ en un proceso de fijación formal que, de manera semejante recogerá Correas unos trescientos años después / Kien te vido $i$ te ve agora/. No sería imposible pensar en el ámbito temático sobre la guerra de Troya como marco de creación de la presente estructura paremiológica, en tanto las secuelas que dejaron esta grave contienda sobre la belleza de Ilión habrían conducido a la apertura de un proceso de fijación a partir de un lamento, entendido en su momento como tópico literario, que con el devenir del tiempo reorganizó sus constituyentes léxicos en la actual estructura conservada:

\begin{tabular}{|l|l|}
\hline \multicolumn{1}{|c|}{ CRÓNICA TROYANA CASTELLANA } & CRÓNICA TROIANA GALLEGA \\
\hline $\begin{array}{l}\text { Ay, Troya! Quien te en otro tiempo vio, si } \\
\text { te agora viesse, non te coñoçería, nin } \\
\text { cuidaría que eras essa (p. 1234) }\end{array}$ & $\begin{array}{l}\text { quen en outro tẽpo uise et quen [te] agora } \\
\text { uee nõ te coñosçería (p. 639) }\end{array}$ \\
\hline
\end{tabular}

La intromisión de las manos del copista/traductor también se trasluce en la eliminación, modificación o adición de las expresiones lingüísticas relacionadas con los juicios de valor, como se trasluce en el acto del asesinato de la madre de Orestes por parte de este. En el texto castellano, la expresión de valor máximo / non ha en el mundo/ seguida de la locución / a tuerto nin a derecho/ pone de manifiesto la posición moral que adopta el autor/copista de dicho texto; en cambio, en la traducción gallega, el copista opta por alejarse del acto en sí mismo a través del empleo único de la voz desaguisado.

De igual modo, el texto castellano toma la perspectiva de los troyanos para enfatizar que el nacimiento de Elena supuso su destrucción, en tanto en la traducción gallega del mismo fragmento, Elena es causa del sufrimiento de los griegos, como así lo refuerza el empleo de la estructura fija / mao día naçeu/:

\footnotetext{
${ }^{14}$ Estructura bimembre formada de un segmento heptasílabo y otro hexasílabo, ambos trocaicos.

15 Octosílabo y hexasílabo trocaicos llanos. Obsérvese la extrema regularidad en la repetición métrica de los ritmos pares.
} 


\begin{tabular}{|l|l|}
\hline \multicolumn{1}{|c|}{ CRÓNICA TROYANA CASTELLANA } & CRÓNICA TROIANA GALLEGA \\
\hline $\begin{array}{l}\text { ca non ha en el mundo razón por } \\
\text { que ningún omne, a tuerto nin a } \\
\text { derecho, deva matar su madre (p. } \\
1427)\end{array}$ & $\begin{array}{l}\text { que fezera desaguisado en matar sua } \\
\text { madre (p. 708) }\end{array}$ \\
\hline $\begin{array}{l}\text { era muy fermosa, a las vezes de } \\
\text { alegría }{ }^{16}, \text { ca era muy leda de coraçón } \\
\text { (p. } 345)\end{array}$ & $\begin{array}{l}\text { era moy fremosa, que aas vegadas era } \\
\text { sandía, et era alegre de coraçõ (p. 278) }\end{array}$ \\
\hline $\begin{array}{l}\text { En talpunto ella fue naçida para los } \\
\text { troyanos, ca por ella son en tal afán, } \\
\text { esperança tan grande e tal } \\
\text { destruimiento (p. 556) }\end{array}$ & $\begin{array}{l}\text { Et mao día naçeu Elena pera os gregos, } \\
\text { ca por ela son metudos en tal traballo } \\
\text { et en tal perígoo (p. 379) }\end{array}$ \\
\hline
\end{tabular}

Sin embargo, otros son los casos que presentan mantenimiento de la misma estructura lingüística para reflejar un idéntico posicionamiento. Esto se observa en el caso de la introducción del inciso de los caballeros que mató Troilo, como obra de caballería en su lance amoroso con Breçaida, que no aparece en el poema francés de Saint-Maure, pero que se mantiene en el texto gallego. Asimismo, parece mantenerse, a modo de estructura cuasiparemiológica, / aquel que bien guarda su cuerpo guarda buen castiello/, posicionamiento moral que también respeta el traductor/copista del texto gallego:

\begin{tabular}{|l|l|}
\hline \multicolumn{1}{|c|}{ CRÓNICA TROYANA CASTELLANA } & \multicolumn{1}{|c|}{ CRÓNICA TROIANA GALLEGA } \\
\hline $\begin{array}{l}\text { Ca más de mill cavalleros tomaron por } \\
\text { ende muerte por sus manos (p. 661) }\end{array}$ & $\begin{array}{l}\text { ca mays de mill caualeyros tomarõ por } \\
\text { ende morte cõ suas mãos (p. 417) }\end{array}$ \\
\hline $\begin{array}{l}\text { ca aquel que bien guarda su cuerpo guarda } \\
\text { buen castiello (p. 927) }\end{array}$ & $\begin{array}{l}\text { ca aquel que ben garda o sseu corpo garda } \\
\text { bõo castelo (p. 530) }\end{array}$ \\
\hline
\end{tabular}

\section{CONCLUSIONES}

Desde la perspectiva arrojada en el presente estudio, el influjo del metro poético y la rima pudieron haber ocasionado la variación de las estructuras lingüísticas todavía en proceso de cambio. Así como el ritmo natural de la lengua castellana fue uno de los

\footnotetext{
${ }^{16}$ En el ms. $A$ de la Crónica troyana se lee "que a las de vegadas era sandia", forma que se corresponde con la gallega, razón por la que esta forma es la que debería predominar en el proceso de collatio del texto castellano. La voz sandia 'loca' (Sánchez-Prieto, 2014) no tuvo que ser exclusivamente genuina del ámbito occidental galaico-portugués, como así lo quiere Juan de Valdés en su Diálogo de la lengua, quien lo explica como resultado del proceso de deformación del latín SANCTE DEUS (Corominas y Pascual, 1983, s.v. SANDIO), en tanto ya aparece documentado en el Libro de Alexandre, Berceo o en Libro de Buen Amor con el mismo significado. En el caso de la obra de Sem Tob ya se relaciona la expresión facial de la risa (felicidad estrechamente vinculada con despreocupación) con el ámbito semántico de la idiotez o la locura: commo el pez el rrío, viçioso y rriyendo, / non piensa el sandío la rred quel van tendiendo (estrofa 393).
} 
factores que influyó en la fijación de las formas lingüísticas y, a su vez, en la evolución del metro poético; en el caso de las paremias, algunas ya plenamente fijadas en la Baja Edad Media, se vieron alteradas, con carácter general, en aras de conformar una unidad lingüística compleja caracterizada por un ritmo (y a veces rima) propio y exclusivo de cada una de ellas que les ha conferido vida propia en la andadura del imaginario común colectivo.

Si bien es cierto que abundan las semejanzas formales como consecuencia directa del método de adecuación palabra a palabra, las diferencias de los usos de las expresiones idiomáticas entre ambas lenguas (en este caso, el castellano y el gallego) no deben reducirse con exclusividad a errores interpretativos o libertades tomadas por el traductor. Los resultados obtenidos en el presente estudio sostienen que la mayoría de los distanciamientos formales de las variantes fraseológicas documentadas en la lengua meta responden a acomodaciones propias de un diasistema lingüístico dado, con la excepción que ofrecen las estructuras paremiológicas que presentan alto grado de fijación en la lengua; por el contrario, las formas libres en proceso de idiomatización, o fijación en el sistema, se ven modificadas por otros avatares lingüístico-gramaticales de la lengua meta (/Quien te en otro tiempo vio, si te agora viesse/ - / quen en outro tẽpo uise et quen [te] agora uee/). En este sentido, el ritmo y la métrica se erigen como constituyentes esenciales, aunque no exclusivos, de la evolución paremiológica, entendida como parte de una teoría fraseométrica. A pesar de que muchos refranes no han mantenido una forma isosilábica con rima interna, sí parece haberse establecido una suerte de isorritmia generalizada que ha permitido su pervivencia a lo largo de la historia, y que los ha diferenciado de sentencias o adagios, entre otras estructuras.

Además, el mismo proceso de adaptación textual está sujeto a amplificaciones, eliminaciones u otros comentarios por parte del copista, especialmente en las formas propias de los juicios de valor, ámbito en el que también encontramos mantenimiento homólogo de las estructuras documentadas en el texto fuente.

La elección de la Crónica troyana promovida por Alfonso Onceno y su traducción gallega de 1373 como campo de estudio contrastivo no resultaba casual, son obras que desprenden una riqueza léxico-fraseológica propia del espacio cultural de la primera 
mitad del siglo xiv, donde el clasicismo, las obras de caballería y el renovado espíritu del amor cortés, propio de los cancioneros, inundan los caminos que conducirán a la eclosión del humanismo.

\section{BIBLIOGRAFÍA}

Anónimo (1976). Historia troyana en prosa y verso, ed. Ramón Menéndez Pidal, Textos medievales españoles. Obras completas de Ramón Menéndez Pidal, XII. Madrid: Espasa-Calpe, pp. 183-419.

Anónimo (1985), Crónica troiana, ed. Ramón Lorenzo. A Coruña: Real Academia Galega / Fundación Barrié.

Anónimo (2007). Libro de Alexandre, ed. Juan Casas Rigall. Madrid: Castalia.

Anónimo (2012). Edición crítica y estudio de la Crónica troyana promovida por Alfonso XI. Tesis Doctoral inédita de Claudia D’Ambruoso, dirigida por Juan Casas Rigall. Santiago de Compostela: Universidade de Santiago de Compostela.

Cantera Ortiz de Urbina, J. (2012). Refranero español. Madrid: Akal.

Corominas, J. y J. A. Pascual (1980-1991). Diccionario crítico etimológico castellano e Hispánico. Madrid: Gredos.

Correas, G. (1967). Vocabulario de refranes y frases proverbiales, ed. Louis Combet. Bordeaux: Institut d'Études Ibériques et Ibéro-américaines de l’Université de Bordeaux.

Echenique Elizondo, M. ${ }^{a}$ T. (2003). Pautas para el estudio histórico de las unidades fraseológicas. En J. L. Girón Alconchel, F. J. Herrero Ruiz de Loizaga, S. I. Recuero y A. Narbona Jiménez (Coords.), Estudios ofrecidos al profesor José Jesús de Bustos Tovar. Madrid: Universidad Complutense, pp. 545560.

Echenique Elizondo, M. ${ }^{a}$ T. (2008). Notas de sintaxis histórica en el marco del corpus de diacronía fraseológica del español (DIAFRAES). En E. Stark, R. Schmidt-Riese y E. Stoll (Eds.), Romanische Syntax in Wandel. Tübingen: Gunter Narr Verlag, pp. 387-397.

Echenique Elizondo, M. ${ }^{a}$ T. y M. ${ }^{a}$ J. Martínez Alcalde (201355). Diacronía y gramática histórica de la lengua española. Valencia: Tirant Humanidades.

Echenique Elizondo, M. ${ }^{a}$ T. y J. P. Sánchez Méndez (2005). Las lenguas de un reino: historia lingüística hispánica. Madrid: Gredos.

Echenique Elizondo, M. ${ }^{a}$ T., Martínez Alcalde, M. J. y J. P. Sánchez Méndez (2016). Perspectivas en el estudio diacrónico de la fraseología en su amplitud hispánica (peninsular, insular y americana). En M. ${ }^{a}$ T. Echenique Elizondo, M. ${ }^{a}$ J. Martínez Alcalde, J. P. Sánchez Méndez y F. P. Pla Colomer (Eds.), Fraseología española: diacronía y codificación. Madrid: CSIC, pp. 17-32.

García-Page Sánchez, M. (2008). Introducción a la fraseología española. Estudio de las locuciones. Barcelona: Anthropos.

Gómez Redondo, F. (2016). Poemas noticieros e historiográficos: Siglos XIII-XIV. En F. Gómez Redondo (Coord.), Historia de la métrica medieval castellana. San Millán de la Cogolla: Cilengua, pp. 185-207.

Lapesa, R. (1992). Alma y ánima en el Diccionario histórico de la lengua española: su fraseología. En J. R. Lodares (Ed.), Léxico e Historia, II. Diccionarios. Madrid: Istmo, pp. 79-86. 
Lorenzo, R., Crónica troiana, en G. Lanciani y G. Tavani (coords.) (1993). Dicionário da literatura medieval galega e portuguesa. Lisboa: Editorial Caminho, pp. 192-193.

Pla Colomer, F. P. (2016). Aproximación a una fraseometría histórica de la lengua castellana: el Libro de miseria de omne y el segundo ciclo del mester de clerecía. En M. ${ }^{\mathrm{a}}$ T. Echenique Elizondo, M. ${ }^{\mathrm{a}} \mathrm{J}$. Martínez Alcalde, J. P. Sánchez Méndez y F. P. Pla Colomer (Eds.), Fraseología española: diacronía y codificación. Madrid: CSIC, pp. 59-74.

Pla Colomer, F. P. (2017). Fundamentos para una fraseometría histórica del español, Rhythmica, 15, pp. 87-112.

Pla Colomer, F. P. (2019). Las paremias de la Crónica troyana promovida por Alfonso Onceno (13121350) en su contexto filológico: inestabilidad, ritmo y fijeza, Revista de Literatura Medieval, 31, pp. 201-216.

Pla Colomer, F. P. (en prensa a). Descripción de los usos fraseológicos en la Crónica troiana gallega (c. 1373) a la luz de los testimonios peninsulares de materia troyana, en Dicenda. Estudios de lengua y literatura españolas.

Pla Colomer, F. P. y S. Vicente Llavata (2017). Aproximación a una fraseología contrastiva en los textos peninsulares de materia troyana: el Libro de Alexandre, la Historia troyana polimétrica y la Crónica troyana de Juan Fernández de Heredia. En M. ${ }^{a}$ T. Echenique Elizondo, M. ${ }^{a}$ J. Martínez Alcalde (eds.) y F. P. Pla Colomer (Coord.), La fraseología a través de la bistoria de la lengua española y su bistoriografía. Valencia / Neuchâtel: Tirant Humanidades / Université de Neuchâtel, pp. 113-153.

Pla Colomer, F. P. y S. Vicente Llavata (2018). Sobre fraseología y fraseometría históricas: la materia troyana en las tradiciones textuales medievales iberorromances. En M. ${ }^{\mathrm{a}}$ T. Echenique Elizondo, A. Schrott y F. P. Pla Colomer (Eds.), Cómo se "bacen" las unidades fraseológicas: continuidad y renovación en la diacronía del espacio castellano. Berna: Peter Lang, pp. 29-54.

Real Academia Española. Banco de datos (CORDE) [en línea: <http://www.rae.es>], Corpus diacrónico del español [consultado el 10 de febrero de 2019].

Sainte-Maure, B. de (1904). Roman de Troie, ed. Léopold Constans. París: Librairie de Firmin Didot.

Sánchez-Prieto Borja, P. (2014). Nebrija, el seseo y la sandía. En R. Díaz Moreno y B. Almeida (Eds.), Estudios sobre la historia de los usos gráficos en español. Lugo: Axac, pp. 73-80.

Vicente Llavata, S. (2011). Estudio de las locuciones en la obra literaria de Iñigo López de Mendoza Marqués de Santillana). Hacia una fraseología histórica del español. Valencia: Universitat de València.

Vicente Llavata, S. (2016). Fraseología hispánica medieval y codificación. A propósito de la traducción aragonesa del Secretum Secretorum promovida por Juan Fernández de Heredia. En M. ${ }^{\text {a }}$ T. Echenique Elizondo, M. ${ }^{a}$ J. Martínez Alcalde, J. P. Sánchez Méndez y F. P. Pla Colomer (Eds.), Fraseología española: diacronía y codificación. Madrid: CSIC, pp. 76-95. 